\title{
Erratum to: Development of an Echocardiographic Scoring System to Predict Biventricular Repair in Neonatal Hypoplastic Left Heart Complex
}

\author{
Christopher Robin Mart • Aaron Wesley Eckhauser
}

Published online: 11 October 2014

(c) Springer Science+Business Media New York 2014

\section{Erratum to: Pediatr Cardiol}

\section{DOI 10.1007/s00246-014-1009-0}

Unfortunately there are two errors in the original version of this article:

1. The description for measuring the mitral valve annulus (at end diastole) in both the manuscript and in the legend for Fig. 4 is incorrect; in addition, Fig. 4a, showing how the mitral valve should be measured, is incorrect.

The correct way to measure the mitral valve is as follows:
The online version of the original article can be found under doi:10. 1007/s00246-014-1009-0.

\section{R. Mart ( $\square)$}

Division of Pediatric Cardiology, Department of Pediatrics, Primary Children's Hospital, University of Utah, 100 North Mario Capecchi Drive, Salt Lake, UT 84113, USA

e-mail: christopher.mart@hsc.utah.edu

\footnotetext{
A. W. Eckhauser Department of Surgery, Primary Children's Hospital, University of Utah, 100 North Mario Capecchi Drive, Salt Lake, UT 84113, USA

e-mail: aaron.eckhauser@hsc.utah.edu
}

The mitral valve annulus $\left(\mathrm{MV}_{4 \mathrm{C}}\right)$ should be measured (in $\mathrm{cm}$ ) in the apical 4-chamber (4C) imaging plane from hinge point to hinge point at full leaflet excursion in diastole. This is shown in the accompanying figure.

2. The original version of this article states that "A nonapex forming LV was seen in $7(41 \%)$ of those undergoing successful $2 \mathrm{~V}$ repair." which is incorrect. The correct statement should read, "A non-apex forming LV was seen in 10 (59\%) of those undergoing successful $2 \mathrm{~V}$ repair." 
Fig. 4 Echocardiographic measurements (in $\mathrm{cm}$ ) used in the calculation of the $2 \mathrm{~V}$ Score. a The MV is measured in the $4 \mathrm{C}$ imaging plane from hinge point to hinge point at full leaflet excursion in diastole. b The AV is measured in the parasternal long axis (PSLA) imaging plane in mid systole. c and d The LV and RV length are measured from the annular plane to the ventricular apex in the $4 \mathrm{C}$ imaging plane at end diastole. The main pulmonary artery is measured at mid systole in either the parasternal short axis (e) or the PSLA (f) imaging plane



